\title{
Traço, forma e dimensão na obra de Vasco Prado
}

\author{
Gaspar Paz \\ Diego de Souza \\ UFES - Universidade Federal do Espírito Santo
}

\section{Resumo}

O objetivo desse estudo é a compreensão do traço livre, da forma e da dimensão na obra de Vasco Prado (1914-1998). Tais aspectos serão analisados a partir da contextualização histórica dos trabalhos desse importante artista brasileiro, na qual destacaremos as influências e as tendências estéticas motivadoras de sua produção. Nesse sentido, pretende-se visualizar a confluência de duas vertentes: a consciência social do artista e sua pesquisa formal. Esses recursos criativos incitam o estudo da "medida" e da "densidade" nas múltiplas leituras e questões da arte contemporânea. Dessa forma, utilizaremos como enfoque teórico as interpretações estéticas de Gerd Bornheim sobre a obra de Vasco Prado e as suas possíveis relações com a noção de "escala" e de "escultura no campo ampliado".

Palavras-chave: Traço livre, forma, dimensão, escultura, escalas, realismo social, expressionismo.

\section{Abstract}

The aim of this study is to understand the free trace, the shape and the dimension in Vasco Prado's (1914-1998) work. We will analyze such elements from the historical context of this important Brazilian artist's work, highlighting the influences and motivating aesthetic trends of his production. In this sense, we intend to interpret the confluence of two aspects: the artist social consciousness and his formal research. These creative features encourage the study of "measure" and "density" in the multiple readings and issues of contemporary art. In this way, the aesthetic interpretations of Gerd Bornheim will be used as theoretical approach on Vasco Prado oeuvre as well as its possible relationship with the concept of "scale" and "sculpture in an expanded field".

Keywords: Free trace, shape, size, sculpture, scales, social realism, expressionism.

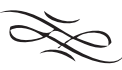


A questão da "medida" (escala) e a maneira de interpretá-la é uma das preocupações das artes contemporâneas. Essa inquietação permeou os trabalhos do escultor Vasco Prado, que atuou também como gravador, ilustrador, desenhista e professor de artes. Em sua formação inicial, Vasco Prado pesquisou técnicas de escultura e estudou na Escola de Belas Artes de Porto Alegre (1940). Em 1941, construiu seu primeiro ateliê e, em seguida (1947-1948) viajou para Paris, como bolsista do governo francês, para estudar com Fernand Léger (1881-1955). Na França, frequentou o ateliê de gravura da École Nationale Supérieure des Beaux-Arts e manteve contato e interlocução com diversos artistas e intelectuais. Em 1949, fundou o Clube da Gravura de Porto Alegre, com Carlos Scliar, Glenio Bianchetti, Glauco Rodrigues, Danúbio Gonçalves, Iberê Camargo e outros. Nesse momento, as questões sociais e formais se intensificaram em sua produção. É nessa relação entre materialidade e sentido que sua expressão, moldada pelo realismo social, assume a pesquisa da linguagem plástica. A partir de 1966, dedica-se ao ensino da escultura em Ateliês e entre 1968 e 1969 viaja novamente pela Europa como artista convidado. Seu trabalho tem cada vez mais reconhecimento nacional e internacional, principalmente pelas esculturas e painéis murais instalados em espaços públicos.

Assim, sua imaginação criadora percorre o mundo das formas e o jogo do traço. A motivação para tais intentos nasce da experiência vivida, da relação com o mundo, da procura pelo "gesto intenso da vida" (PRADO, 1984, p. 9). Portanto, revela Vasco Prado, são "as experiências que comandam as exigências formais" (Idem). É com essa liberdade que o artista constrói os recursos para seu estilo criativo. Entre tais aspectos destacam-se o uso do elemento abstrato (ainda que o pano figurativo não tenha sido totalmente abandonado), a valorização da forma (sem enfeites ou ornamentos), a monumentalidade das obras (que não se definia pela quantidade ou tamanho das peças, mas pela exploração das linhas curvas, pela sensualidade do traço e pela extensão da superfície), as alusões e referências ao elemento telúrico e a tipificação, bem como as influências do expressionismo. A assimilação do expressionismo apresentava muitas facetas em nossas paragens. E no caso das artes plásticas é notável a presença de Lasar Segall. Artistas como Iberê Camargo, revelavam o importante impacto do expressionismo em suas produções. A obra de Vasco Prado, segundo críticos como Manoel Sarmento Barata e Marc Berkowitz, se abre para um expressionismo "muito diferenciado e pessoal, com uma dicção que é fluente, harmoniosa, mas ao mesmo tempo severa e tensa" (Sarmento, in PRADO, 1984, p. 12).

Todos esses aspectos, segundo Gerd Bornheim, caracterizam a topografia da criatividade de Vasco Prado. A atualidade do trabalho do escultor se inscreve principalmente numa reação contra valores e padrões estéticos. Esta era uma inclinação geral da época, problematizada através da expressão das vanguardas artísticas. Estava expressa no desenvolvimento e nas transformações do itinerário de diversos artistas da tradição escultórica, como Brancusi, Calder, Amilcar de Castro, Lygia Clark, Bez Batti. Nem há como pensar, atualmente, a estética de um Ron Mueck, sem atentarmos para esse cenário. Vasco Prado percebia todas as nuances e rupturas que apareciam no horizonte das 
artes e da política de seu tempo. Entendia, assim, a relação direta de algumas expressões artísticas com o meio atuante, com a escala e suas dimensões em relação ao corpo do espectador, a paisagem, a arquitetura, entre outros.

Nessa perspectiva, interpretamos algumas de suas obras escultóricas para entender os significantes de suas produções, tanto nas escolhas dos temas quanto das linguagens utilizadas pelo autor. Dessa forma, faremos um pequeno recorte, comentando alguns de seus trabalhos a fim de acedermos a certas especificidades de sua obra.

Em tal leitura, estão implícitas discussões teóricas importantes dentro do panorama das artes, tais como: a escultura no campo ampliado, a produção iconográfica da escala, bem como questões em torno da crítica artística e da experiência estética. Tais incursões podem ser analisadas a partir de dois vieses, flagrados por Bornheim na obra do escultor.

De um lado, a sua aguda consciência social e o seu olhar seduzido por tudo o que é humano; mas de outro, a mestria com que deixa correr o traço livre, obediente a uma necessidade interna derivada do formal. O nervo da estética de Vasco Prado situa-se precisamente neste ponto: na confluência destas duas raízes (BORNHEIM, 1998, p.143).

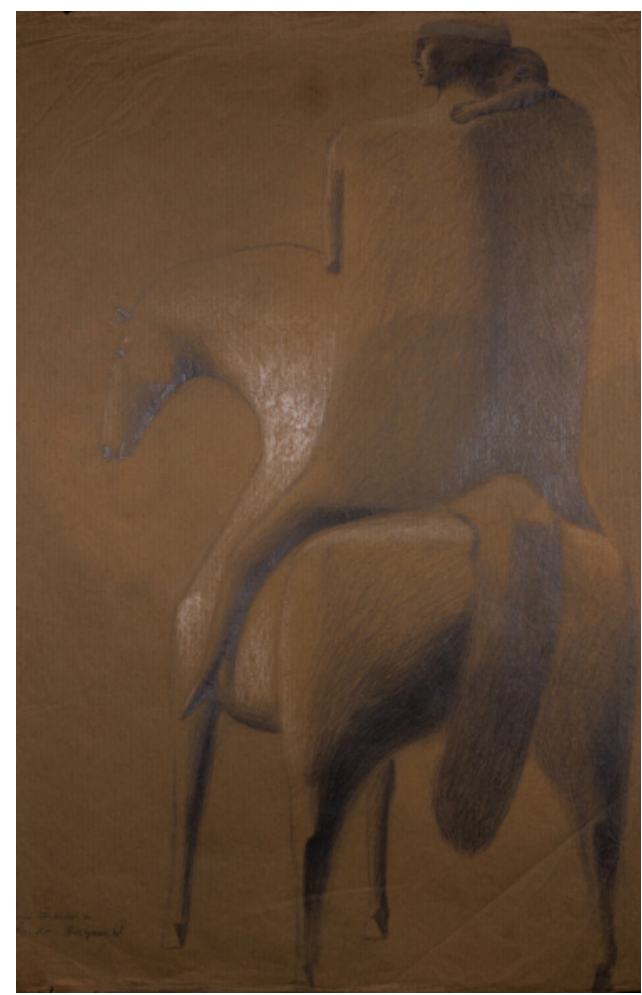

Sem título, Varsóvia, 1968 Desenho a lápis sobre papel Kraft, $63,3 \times 100,3 \mathrm{~cm}$

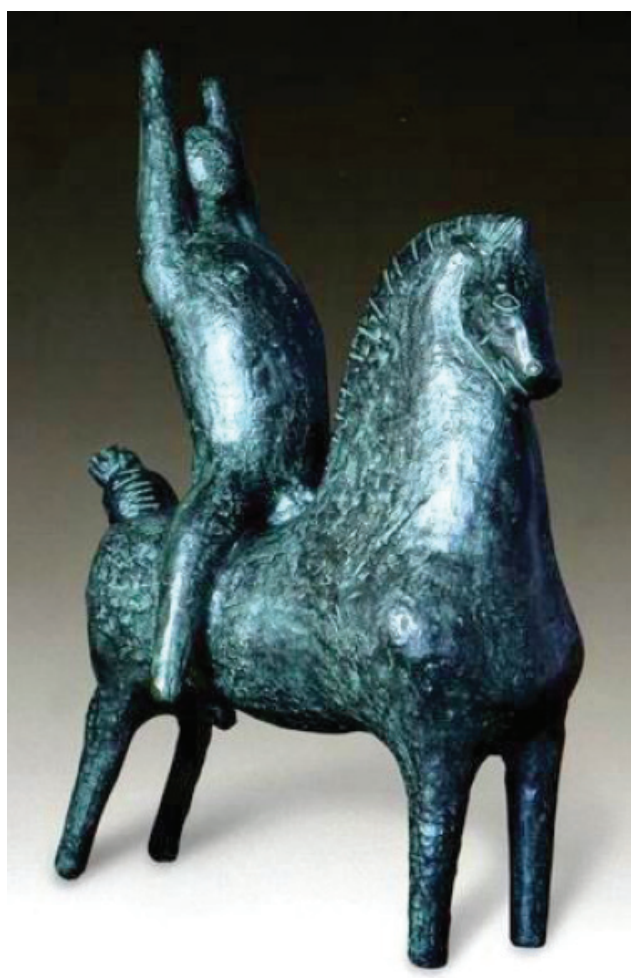

Homem a cavalo, s/d

Bronze 
Essas duas raízes se destacam, por exemplo, na relação entre o desenho e a escultura de Vasco Prado. Nesse sentido, percebe-se claramente que a pesquisa formal motivou a migração do traço e das ranhuras, características de seus desenhos, para suas esculturas e vice-versa. Tais características são preservadas até mesmo naquelas esculturas, cujo polimento é mais evidente. Talvez pudéssemos intuir que alguns desses desenhos são estudos para produções escultóricas.

Comparando os dois trabalhos, pode-se notar que Vasco Prado lança mão de todo um grafismo e da intensificação de ângulos e dimensões geométricas em seu desenho para criar situações escultóricas. O mesmo pode ser conferido se fizermos o caminho inverso, observando a transposição das características estéticas do material esculpido para o desenho. Nesse caso, o desenho assumiria o estatuto de uma "escultura bidimensional". Tais incursões imprimem em seus trabalhos significantes singulares. Notamos aqui o domínio de cada uma dessas formas de expressão através do estilo peculiar do autor, que modela seus materiais produzindo uma espécie de economia da forma. Aliás, essa simplicidade se congrega com a versatilidade no uso de diversos materiais, tais como: a terracota, o mármore, o alumínio, o bronze, entre outros. Nos anos 1980, Vasco Prado diz a Manoel Sarmento Barata que "na linguagem da escultura, só há substantivo". São os próprios posicionamentos do autor relativos à linguagem plástica que passam a transparecer. Para Barata, o uso substantivo da linguagem, neste caso, revelava suas restrições "com o adjetivo, o acréscimo, a aderência retórica" (Manoel Barata in PRADO, 1984, p. 12). Ou seja, o magma de sua escultura se apresenta despido de ornamentos, mas como bem ressaltou Bornheim, com um interessante "componente sensual". Essa sensualidade é expressa pelas linhas curvas e pelas formas arredondadas, indicando na obra de Prado o "comércio com o elemento abstrato" (BORNHEIM, 1998, p.151). Além disso, a simplificação da forma se reveste de elementos telúricos e de pressupostos do realismo social assumidos pelo artista. Para Bornheim, esse realismo social "significa, precipuamente, que a obra de nosso artista é essencialmente figurativa” (Idem, p, 149). Contudo, o filósofo adverte que "tudo depende, então, de bem interpretar os limites desse figurativismo, ou o seu alcance” (Idem, p, 149). São justamente as inquietações entre o formalismo e as posições sócio-políticas do autor, que ganham relevo. No fundo, sua proposta tinha como pedra de toque o interesse pelo mundo humano, pela natureza, pelas causas sociais. São esses temas que incitam a vigorosa participação política de Vasco Prado, como ressaltam os escritores Jorge Amado, seu camarada do Partido Comunista, e Érico Veríssimo.

Essas posições e responsabilidades políticas movimentam sua produção na medida em passam a falar direta e indiretamente como o meio, mediante, por exemplo, algumas escolhas de pedestais não tradicionais para esculturas, ou até mesmo com a definição de temas recorrentes. A mulher, o cavalo, o homem e seus anti-heróis estarão presentes ao longo de todo esse percurso. Cabe ressaltar que essas escolhas levaram em conta a influência do niilismo expressionista e sua reação contra paradigmas da tradição artística. Essas preocupações situaram a relação da obra com o ambiente, principalmen- 
te nos trabalhos expostos em espaços públicos. Em alguns casos, como o de "Pomona", a intersecção entre os elos formais e sociais se intensificam.

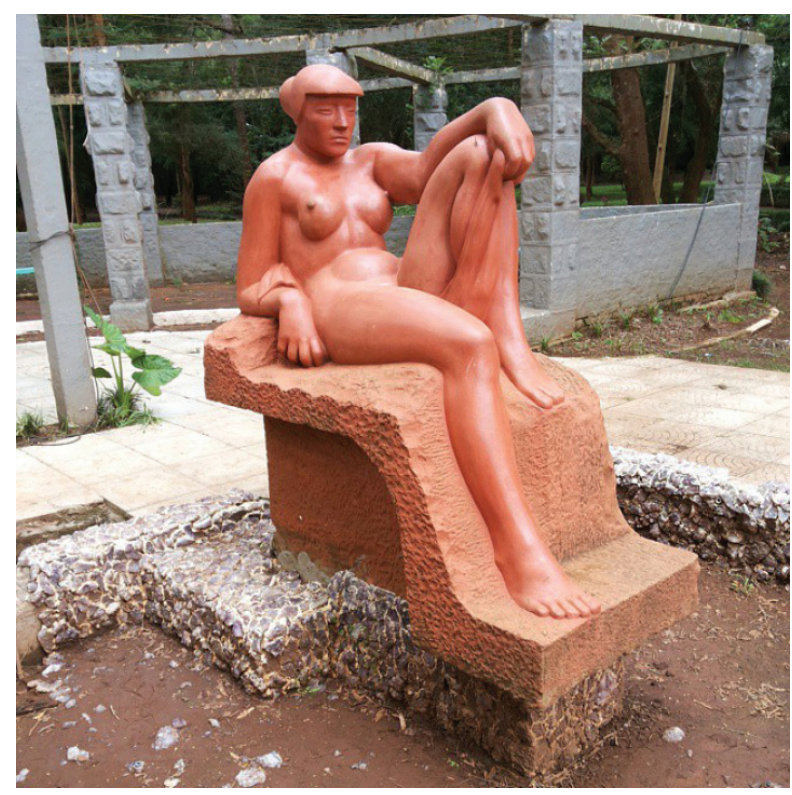

Pomona, escultura em Arenito Rosa, 1950. Local: Parque do Balneário Oswaldo Cruz. Vasco Prado

Em "Pomona", Vasco Prado traz à tona o que poderíamos chamar de escala-corpo, ou seja, a pesquisa das dimensões e do livre jogo da forma aliada a incursão sociocultural por uma aldeia indígena, onde o artista teve contato com uma jovem da tribo Kaingang. É daí que brota o trabalho com esse bloco único de pedra arenito rosa, instalando no parque do Balneário Oswaldo Cruz, na cidade de Iraí, Rio Grande do Sul. "Pomona", segundo a mitologia romana, é a Deusa das frutas e dos jardins. Para Prado, a jovem indígena representava justamente o signo da vitalidade da terra. Tudo está em jogo na trama estética de Prado: o material (granito avermelhado, que remete aos rituais corporais indígenas) é moldado para repousar sobre um espelho d'água. É toda uma reconstituição do espaço, das circunstâncias e dos significantes que projetam na obra a aldeia, a índia, a deusa, a mulher, a pele vermelha, a força, a pedra, o lago, a água. A confluência e o arranjo de tais elementos é semelhante àquela problematizada por Didi-Huberman quando se refere à obra do escultor Giuseppe Penone: "Enunciar esta questão equivale a tocar com o dedo a diferença entre uma escultura que fabrica objetos no espaço - objetos de espaço, poderíamos dizer - e uma escultura que transforma os objetos em sutis atos do lugar, em ter-lugares" (DIDI-HUBERMAN, 2009, p.45).

É justamente essa abertura das significações do espaço que notamos na Pomona de Prado. A composição dos elementos imagéticos (a partir da costura social e formal), redefinem pelo traço, os atos do lugar. Está dado aí um dos grandes temas do artista: a força da mulher em toda sua potência poética. 
Outro tema recorrente na obra de Vasco são seus anti-heróis, tais como as esculturas "Negrinho do Pastoreio" e o "Tiradentes", ambas pensadas para o espaço público. Nessa perspectiva, essas obras retomam com veemência a raiz do realismo social, visto que são produções que incitam a reflexão política. Em tais ações o escultor trabalha com uma espécie de universal negativo, recusando assim as estéticas miméticas que se constituíam pelos universais concretos (os reis, o cristo, a norma, a deusa justiça, entre outros).

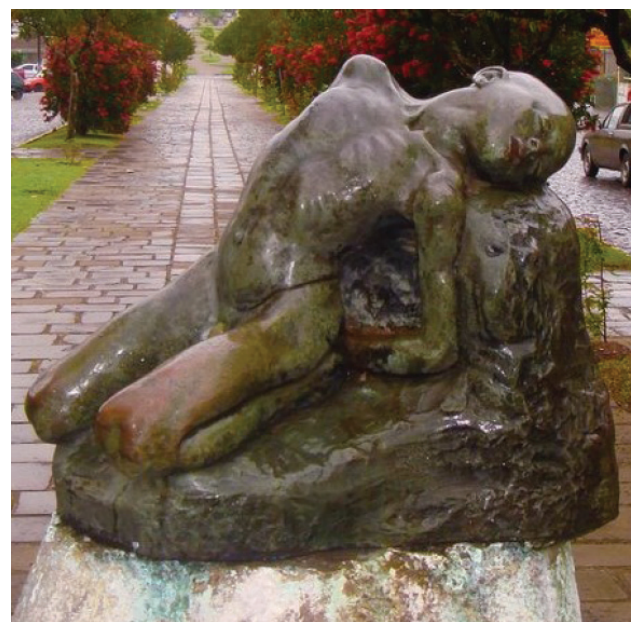

Negrinho do Pastoreio. Bronze, 1943.

São Francisco de Paula, RS.

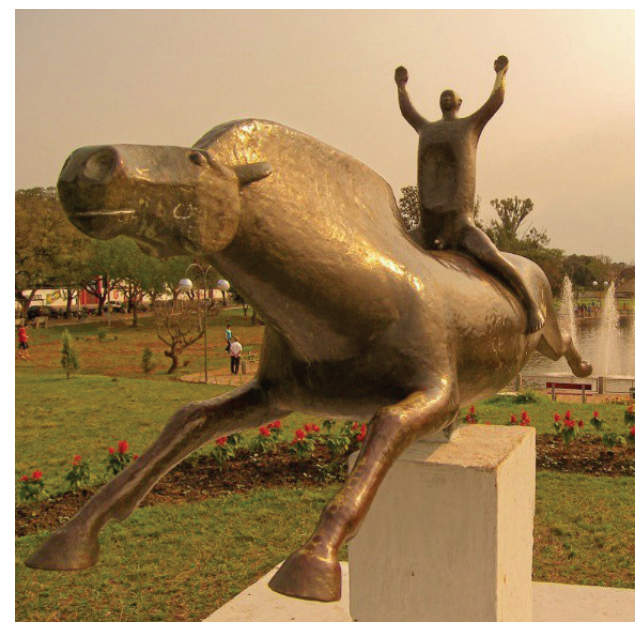

Negrinho do Pastoreio triunfante. Bronze, 1968 Alegrete, RS.

Nessa temática percebe-se como o autor pretendia que suas obras falassem ao espectador. Em seu primeiro Negrinho do Pastoreio, de 1943, nos deparamos com o martírio da lenda, no qual o personagem aparece sentado sobre as próprias pernas e preso a um formigueiro. Resta-lhe apenas a dor, o sofrimento. Destituído da dignidade, qual seria a sua sina? A morte, a agonia? Na escultura de 1943 ainda se preserva a admiração por Rodin e o legado de suas expressões. Nessas esculturas, a maestria de Prado é flagrante, sobretudo se pensarmos na maneira com que dispõe as escalas iconográficas do corpo. $\mathrm{O}$ artista redimensiona o imaginário lendário e regional do Sul com o intuito de desalienar o espectador. No Negrinho do Pastoreio de 1968, mostra-nos um jovem a cavalgar, livre e de braços erguidos como que a desbravar horizontes. De fato, esta obra não é estática e fala de prosseguimentos. É nesse sentido que Bornheim chama atenção ao fato do Negrinho do Pastoreio ser uma espécie de universal, já que

[...] ele sintetiza paradigmaticamente as consequências da escravidão. A alienação nem está tanto na marginalidade do Negrinho, e sim naqueles que acendem velas a seus pés. Um universal, sim, mas com um adendo em tudo revelador: ele é um universal negativo, ou 
o avesso do universal, e, por isso mesmo, figura fortemente politizadora (BORNHEIM, 1998, p.151).

Para Bornheim, a importância do trabalho de Vasco Prado se revela no enlace de todos esses modos de expressão. A valorização da produção e do estilo desse autor é de extrema importância para o estudo e a compreensão do desenvolvimento das artes plásticas e visuais no Brasil.

\section{Referências bibliográficas}

BORNHEIM, Gerd. "Vasco Prado: as dimensões de sua escultura". Em Páginas de Filosofia da Arte. Rio de Janeiro: UAPÊ, 1998.

Prêmio, 1994.

. "Bez Batti”. Em Bez Batti: escultura em basalto. São Paulo:

. "A pintura que é pintura". Texto se apresentação para o catálo-

go da exposição Glenio Bianchetti 50 anos de arte realizada em agosto de 1999 no Palácio do Itamaraty em Brasília.

DIDI-HUBERMAN, Georges. Ser crânio: lugar, contato, pensamento, escultura. Belo Horizonte: C/Arte, 2009.

KLINTOWITZ, Jacob. Vasco Prado: gravador, desenhista, escultor: ele aprende as coisas que seu coração dita. Skultura, São Paulo, 1984.

KRAUSS, Rosalind. A Escultura no Campo Ampliado. Gávea, Rio de Janeiro, v.1, p. 87-93, 1984.

. Caminhos da escultura moderna. São Paulo: Martins Fontes, 1998.

MAMMI, Lorenzo. O que resta. São Paulo: Companhia das Letras, 2012.

MUECK, Ron. Catálogo da exposição no MAM (Rio de Janeiro). Textos de Justin Paton e Robert Storr. Brasília: Ministério da Cultura/ Fondation Cartier pour l'art contemporain/ Fundacíon Proa, 2014.

PAZ, Gaspar. Interpretações de linguagens artísticas em Gerd Bornheim. Tese de doutorado em Filosofia - Instituto de Filosofia e Ciências Humanas. Rio de Janeiro: UERJ, 2010.

PRADO, Vasco. Vasco Prado. Porto Alegre: Galeria Tina Presser, 1983.

Vasco Prado (catálogo). Museu de Arte do Rio Grande do Sul; São 
Paulo: Companhia Iochpe de participações, 1984. (Reproduções de esculturas, desenhos e gravuras, biografia do autor, lista de exposições e prêmios. Textos de Marc Berkowitz e Manoel Sarmento Barata e depoimentos de Erico Veríssimo, Jorge Amado e outros).

. Vasco Prado. Entre-falas: artista. Os depoimentos prestados pelo artista a Evelyn Berg Iochpe, então diretora do Museu de Arte do Rio Grande do Sul. Acessível em http://www.margs.rs.gov.br/ndpa_sele_vasco.php. 